\title{
Traduções Oríentadas
}

Oriented Translations

\section{Desirée Francine dos Santos ${ }^{1}$}

1 Graduada em Letras - Língua Portuguesa pela Universidade Federal de Ouro Preto (2012). Mestra em Letras pela Universidade Federal do Paraná (2016). Doutoranda em Literatura pela Universidade Federal de Santa Catarina. É artista visual, poeta, tradutora e professora de Português e Literaturas.

Currículo lattes: http://lattes.cnpq.br/9641278287404611

ORCID: https://orcid.org/0000-0001-6298-5915

E-mail: desireefsantos@gmail.com 


\title{
Resumo
}

Neste ensaio proponho unir artes visuais e literatura para pensar traduções feitas a partir de autorias negras. A partir de uma provocação linguística, busco emergir as traduções oríentadas (como no conceito metafísico yorubá da palavra orí), bem como discutir os novos imaginários que compõem o campo artístico-literário nos dias de hoje. Portanto, Beatriz Nascimento, Yhuri Cruz, Rosana Paulino e Conceição Evaristo são pessoas que utilizam uma tradução oríentada, a partir de direcionamentos relacionados a um diálogo político, étnicoracial e de gênero.

\section{Palavras-chave}

Autorias Negras; Artistas Negres; Artes Visuais; Literatura; Traduções Oríentadas.

\begin{abstract}
I propose to unite visual arts and literature in this essay to think about translations made by black authorship. As the result of a linguistic provocation, I seek to emerge oriented translations (as in the metaphysical concept of the Yoruba word ori), as well as to discuss new imaginaries that compose the artistic-literary field today. Therefore, Beatriz Nascimento, Yhuri Cruz, Rosana Paulino, and Conceição Evaristo are people who use an oriented translation based on directions related to an ethnic-racial, political and gender dialogue.
\end{abstract}

\section{Key words}

Black Authorships; Black Artists; Visual Arts; Literature; Oriented Translations.

ISSN: 2447-1267 


\section{Insegurança}

[A Drummond. 23.01.1988]

Nasci segura em rede esticada

Em praia de claras águas

Em ventre bom e gostoso de poderosa mulher

No caminho topei com a primeira pedra

Grito de terror diante da luz

Senti-me insegura, primeira expressão de náusea

Nasci segura em mãos experientes

Entre sábias mulheres com muita atenção

Coisa viva, animada

No caminho topei com a segunda pedra

Grito de terror diante da treva

Senti-me insegura, o primeiro vômito

Nasci segura entre corações amorosos

Leite, doce, pão e mel em abundância

No caminho topei a terceira pedra

Grito de terror diante de ser

Senti-me insegura, a primeira insônia

Anúncio de ser mulher.

Beatriz Nascimento

No caminho topei a quarta pedra, senti-me insegura, o ano é 2021 . O contexto pandêmico perdura e segue amplificando os espetáculos de horror e violência social projetadas por um governo genocida aqui no Brasil. Curioso que em 1988 quando Beatriz Nascimento (1942 - 1995) escreveu Insegurança eu, também mulher negra, era recém nascida e ainda assim hoje consigo assimilar o que ela pontua como falta de segurança. Nossos caminhos se entrecruzam numa corporalidade similar na diáspora, porque nascer segura e sentir-se insegura é muito coerente na anunciação de ser mulher negra nascida no Brasil. De acordo com o Atlas da Violência 2020 organizado pelo Instituto de Pesquisa Econômica Aplicada (Ipea) e pelo Fórum Brasileiro de Segurança Pública (FBSP) só "em 2018, 68\% das mulheres assassinadas no Brasil eram negras" (destaque da própria fonte). As inseguranças rondaram Cláudia Silva Ferreira (morta aos 38 anos em 2014), Marielle Franco (morta aos 38 anos em 2018), Ágatha Vitória Sales Félix (morta aos 8 anos em 2019), assim como a própria Beatriz cuja 
vida, infelizmente, foi ceifada aos 52 anos sendo vítima de misoginia e feminicídio. A sociedade brasileira até hoje aguarda o desfecho dos casos de Cláudia, Marielle e Ágatha, nítidos exemplos de um Estado genocida e da truculência policial que atingem populações dissidentes.

Insegurança é um poema até então inédito publicado em 2015 em Todas [as] distâncias: poemas, aforismos e ensaios de Beatriz Nascimento livro organizado por Alex Ratts e Bethânia Gomes, publicado pela editora Ogum's Toques Negros. Alex Ratts é antropólogo, geógrafo e poeta; Bethânia Gomes além de bailarina, professora de dança e diretora também é filha de Beatriz Nascimento.

Beatriz era uma potência extraordinária de vida, era mulher negra, nordestina, migrante, professora, historiadora, poeta, ativista, pensadora, assim como bem aponta Alex Ratts na sua anterior pesquisa sobre Beatriz Nascimento publicada em 2006 no livro Eu sou atlântica: sobre a trajetória de vida de Beatriz Nascimento editado pela Imprensa Oficial do Estado de São Paulo e pelo Instituto Kuanza.

O poema Insegurança é escrito por Beatriz Nascimento em janeiro de $1988 \mathrm{com}$ dedicação para Carlos Drummond de Andrade. Esta dedicatória feita a Drummond por Beatriz Nascimento nos direciona, não por acaso, tanto ao escritor mineiro quanto ao poema denominado No meio do caminho. Ouso dizer que a "topada da pedra de Beatriz" é uma tradução de no meio do caminho tinha uma pedra de autoria de Drummond, como uma zona de contato estabelecida, um elo criado entre eles. Como se Beatriz tivesse se conectado intimamente com a leitura de Drummond e transformado em magia um poema em outro poema, uma resposta, um diálogo possível.

É bom mencionar já de antemão que as traduções não se encontram somente entre textos escritos ou entre línguas diferentes como muitas pessoas podem imaginar; traduzir é uma prática muito mais ampla, é também transformar, é (re)criar a partir de uma ideia já estabelecida textualmente ou não. Por isso, recorro à Beatriz para observar o quanto há de tradução no poema Insegurança, encarando a tradução como uma maneira que ela teve, com seu próprio olhar e perspicácia, de digerir a 'pedra no meio do caminho' colocada por Drummond lá atrás em sua primeira publicação na Revista Antropofágica em 1928 - a tal famosa pedra que hoje parece intransponível.

Pegando um embalo em outras produções realizadas por Beatriz Nascimento além de poemas, vale mencionar a construção do roteiro, narração e pesquisa para o documentário Ôrí dirigido por Raquel Gerber, em 1989. Ôrí é um documentário que possui um aprofundamento direcionado à movimentação da história negra no Brasil entre os anos 1977 a 1988. A palavra orí é de origem yorubá e significa literalmente cabeça, podendo ter seu significado ampliado nas religiões de matriz africana. Ressalto, também, que há neste documentário uma outra contribuição valiosíssima para a compreensão das dinâmicas históricas do nosso país acerca do racismo brasileiro, da negritude, das territorialidades, dos quilombos, de crenças, e acerca da própria personalidade de Beatriz ao se denominar como atlântica.

Longe de querer esgotar a interpretação do instigante poema que abre esse 
nosso diálogo, podemos continuar pensando nas dinâmicas de tradução que se entrecruzam no campo artístico-literário-interdisciplinar.

\section{Do silenciamento ao grito}

Recentemente encontrei uma tradução bastante inovadora para a imagem de Anastácia, uma mulher negra - inclusive bastante conhecida no imaginário afrodiaspórico do Brasil - que foi escravizada e condenada a usar um colar de ferro e uma máscara de flandres. Há algumas versões sobre a história de Anastácia as quais nos indicam que "Anastácia era filha de uma família Kimbundo, nascida em Angola, sequestrada e levada para a Bahia (...) Outros alegam que ela teria sido uma princesa Nagô/Yorubá (...) Enquanto outros ainda contam que a Bahia foi seu local de nascimento" (KILOMBA, 2019).

Acredito que já nos habituamos a escutar histórias da população negra que prosperam com grandes lacunas e sem muitas possibilidades de resposta. Mas há a informação de que Anastácia morreu de tétano devido ao colar de ferro que usava ao redor de seu pescoço. Assim, pintada por um francês por volta de 1817, Anastácia foi representada e imortalizada com a máscara que a emudece, transformando-a em um símbolo da tortura escravagista. Contam também que Anastácia não era seu nome de batismo e que foi inclusive santificada, porque ela tinha "poderes de cura imensos e que chegou a realizar milagres" (KILOMBA, 2019). E não é de hoje que mulheres com grandes poderes, inclusive de cura, são demonizadas e tolhidas de seus conhecimentos e rituais. Atualmente Anastácia é celebrada e cultuada como santa no dia 12 de maio.

Introduzo esta história pra dizer que foi, ao meu ver, uma inovação a tradução do artista visual, escritor e dramaturgo negro Yhuri Cruz, denominada Anastácia Livre. Uma tradução no sentido de cura, emancipação e magia na qual Cruz (re)cria a figura de Anastácia sem o colar de ferro e a máscara facial que sempre foram reproduzidos por várias outras imagens-traduções do primeiro e até então único retrato dela. Desde então a tradução de Yhuri Cruz é a única imagem que se tem de Anastácia sem a máscara de flandres quando se busca no Google por "Anastácia sem máscara". Nesta nova representação abre-se a oportunidade para a criação de uma nova narrativa, de novos olhares para uma representação já muito petrificada em nosso consciente imagético.

Figura 1: https://redesoberania.com.br/anastacia-simbolo-da-via-crucis-das-mulheres-negras-daescravidao-aos-dias-atuais/

Esta tradução de Yhuri Cruz me faz lembrar bastante dos debates de bell hooks em seu livro Olhares negros: raça e representação (1992) traduzido para o português brasileiro por Stephanie Borges em 2019. Neste livro bell hooks incita um novo olhar, um olhar insurgente para as artes de modo geral, nos desloca o sentido para a confrontação de um olhar colonizado que podemos ter ainda nos dias de hoje, fruto 
do que nossa linhagem hereditária já vivenciou. É como se nós devêssemos nos ater a todas as brechas colonialistas que sempre nos fizeram enxergar o belo no outro e nos fizeram odiarmos a nós mesmas, ou como se percebêssemos a função do olhar não somente para a visão, mas percebêssemos, também, as epistemes visuais e os controles que são estabelecidos sobre o direito de olhar. O próprio artista noticiou, em sua rede social, que Anastácia Livre fará parte de materiais didáticos de História a partir de 2020 e pelos próximos cinco anos, isso já indica o quão revolucionária se torna esta tradução. A perspectiva trazida por Cruz em seu post no Facebook nos retoma essa rebeldia do olhar, um grito, novas maneiras de encarar o passado:

Não devemos crer que nossa relação com o passado deva ser jogada fora porque não foi agradável, e que por isso não devemos olhar pra trás. O passado é infinito e somos parte disso com um corpo infinito de subjetividades. São muitas bocas, muitos pés, muitas mãos e muitos corpos que construíram quem somos. E somos além. É necessário viajar no tempo e emancipar (passados e futuros). Inventar e fabular nossos instrumentos de emancipação agora. (CRUZ, 2020)

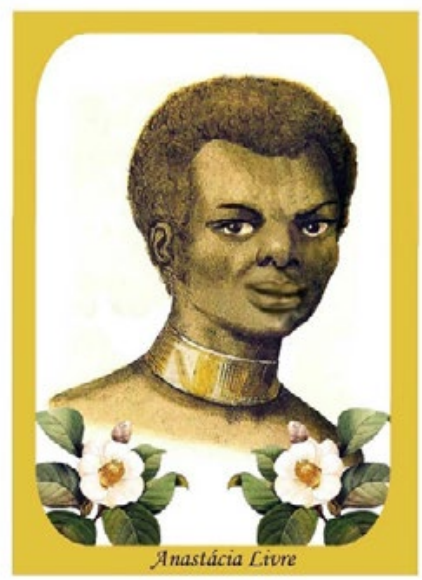

Figura 2: Monumento à voz de Anastácia, 2019, Santinho, $10 \times 7 \mathrm{~cm}$ (Fonte e autoria: Yhuri Cruz). Monumento à voz de Anastácia, 2019, Santinho, 10 × 7cm (Fonte e autoria: Yhuri Cruz)

Pensando a partir do nosso olhar ao passado e ainda sobre esses movimentos que podem retomar memórias de silenciamentos, mas sendo abordados de outra maneira, lembro-me também da ontológica exposição da importantíssima artista visual negra Rosana Paulino denominada Rosana Paulino: A Costura da Memória, a qual reúne várias obras produzidas em 25 anos de carreira. Uma delas exibe

uma série de suportes para bordar com figuras de mulheres de sua família impressas em tecido cujos olhos, bocas e gargantas estão costurados, indicando o emudecimento imposto às mulheres negras, muitas vezes fruto da violência doméstica. (PINACOTECA, 2020)

Essa série com olhos, bocas e gargantas costurados é muito profunda, pois 
nos leva para esse lugar exato do silenciamento forçado, da cegueira forçada, da impossibilidade da fala e, consequentemente, da própria existência. Essa exposição da Paulino esteve presente na Pinacoteca de São Paulo e no Museu de Arte do Rio (MAR) entre 2018 e 2019. Inclusive a própria artista costuma mencionar em entrevistas que só consegue trabalhar com aquilo que a incomoda e acrescenta que o seu incômodo foi perceber a falta de representatividade negra nas artes - isso a impulsionou fervorosamente a produzir o que ela produz.

Cabe aqui dizer que a criação-tradução de Yhuri e de Rosana partem de objetivos diferentes, de formas de denúncias diferentes, mas possuem o mesmo foco: foco na ferida, na ferida aberta pelo colonialismo. Rosana Paulino está justamente traduzindo as dores e violências que nos silenciaram no passado, para evitar a repetição, para que essas mesmas violências de novo não aconteçam. Rosana reivindica, recupera traumas. Já Yhuri Cruz direciona o olhar para o passado e recria a figura de uma mulher negra que sempre teve sua iconografia ligada diretamente à tortura, ou seja, retoma uma representação cristalizada socialmente e a reconfigura trazendo um semblante de liberdade e emancipação. Enquanto Yhuri está retirando a máscara de Anastácia, Rosana está costurando a boca de mulheres de sua família nos provocando, nos despertando o olhar para muitas realidades, demonstrando uma espécie de fúria necessária contra diversas violências.

Sem deixar de fazer menção ao momento histórico em que estamos vivenciando no país, no qual a conjuntura política nos emudece crescentemente, é de suma importância poder fazer reflexões sobre as políticas de controle e genocídio instauradas nos nossos cotidianos. Práticas de racismo, fascismo, xenofobias, LGBTQIA+fobias, toda e qualquer tipo de violência tem ganhado destaque repercutindo drasticamente nas leituras que podemos fazer da própria ideologia contida e explícita no ato de silenciamento.

Sobretudo, traduzir oríentadamente a partir de uma simbologia mais amplificada e complexa da palavra orí, que vai para além do que significa cabeça, é ter discernimento e intuição sobre os legados afro-diaspóricos já construídos e garantir com eles a sedimentação para novas bases de diálogos. Traduzir de forma oríentada é selecionar e restringir o foco de nossos olhares e interações para as urgências artísticas negras dentro desses campos artísticos dialogados aqui. Yhuri Cruz e Rosana Paulino são, portanto, dois exemplos de tradutores oríentades.

\section{Leite, doce, pão e mel em abundância: o chamamento de vida}

Arrisco dizer que a tradução Anastácia Livre é a cura de Anastácia assim como a reflexão sobre mudanças possíveis no agora. Arrisco também dizer que quando Beatriz dedica a Drummond seu poema, ela traduz sua atenção às pedras no caminho e a replica contando sua trajetória. É como uma abertura de processos de cura que podem surgir a partir de uma conexão de forças, de uma magia. 
A cura e a magia vêm da criação-tradução das artes, da literatura, da escrita, da música, de diversas maneiras. Conceição Evaristo, conhecida também como nosso baobá da literatura, costuma dizer em entrevistas que a literatura tem que servir para nós que precisamos tanto e que, inclusive, a arte deve chegar onde a vida é sonegada. E assim ela segue afirmando que quando a gente lê e se emociona e percebe semelhança por alguma personagem isso significa um chamamento de vida. Ampliando os olhares, o chamamento de vida pode sim estar nas palavras escritas, nos textos diversos, em ilustrações e pinturas, nas traduções de modo geral.

Cabe, por fim, dizer também que a tradução nunca foi só uma ponte que conecta um lado a outro lado, a escrita e as artes visuais também nunca foram só uma ponte ou um lugar de mera decodificação. E por isso mesmo este ensaio se encerra como em reticências, apresentando a vocês uma outra tradução. Dessa vez, nomeio também como tradução o poema de Conceição Evaristo escrito em memória de Beatriz Nascimento, uma tradução tocante e extremamente necessária para a perpetuação de uma personalidade tão afetuosa. Sugiro leitura em voz alta:

A noite não adormece nos olhos das mulheres

[Em memória de Beatriz Nascimento]

A noite não adormece

nos olhos das mulheres

a lua fêmea, semelhante nossa,

em vigília atenta vigia

a nossa memória.

A noite não adormece

nos olhos das mulheres

há mais olhos que sono

onde lágrimas suspensas

virgulam o lapso

de nossas molhadas lembranças.

A noite não adormece

nos olhos das mulheres

vaginas abertas

retêm e expulsam a vida

donde Ainás, Nzingas e Ngambeles

e outras meninas luas

afastam delas e de nós

os nossos cálices de lágrimas. 


\begin{abstract}
A noite não adormecerá
jamais nos olhos das fêmeas

pois do nosso sangue-mulher

de nosso líquido lembradiço

em cada gota que jorra

um fio invisível e tônico

pacientemente cose a rede

de nossa milenar resistência.
\end{abstract}

\title{
Conceição Evaristo
}

A noite não adormece nos olhos das mulheres é um poema que Conceição Evaristo ofereceu à Beatriz em vida e ela, com muita poética e sensibilidade, o retornou à Conceição com o acréscimo do nome Ngambeles. Poderíamos, então, considerar este atravessamento de ambas em suas escritas como uma tradução oríentada? Deixo a resposta no ar onde o vento corre e as ideias passeiam. Orí, nas palavras de Beatriz Nascimento é

a iniciação de um novo estágio da vida, uma nova vida, um novo encontro. Ele se estabelece enquanto rito e só por aqueles que sabem fazer com que uma cabeça se articule com ela mesma e se complete com seu passado, com seu presente, com seu futuro, com a sua origem e com seu momento ali. (ORÍ, 1989)

\section{Referências}

CÔRREA, Michele. Anastácia: símbolo da via-crúcis das mulheres negras, da escravidão aos dias atuais. Rede Soberania. Rio Grande do Sul, 13 mai 2018. Disponível em <https:// redesoberania.com.br/anastacia-simbolo-da-via-crucis-das-mulheres-negras-da-escravidaoaos-dias-atuais/>. Acesso em: 12 jan. 2021.

CRUZ, Yhuri. Facebook: Yhuri Cruz. Rio de Janeiro (Rio de Janeiro), 12 mai. 2020. Disponível em <https://www.facebook.com/yhuri.cruz>. Acesso em: 10 jan. 2021.

EVARISTO, Conceição. A noite não adormece nos olhos das mulheres. In: RATTS, Alex; GOMES, Bethânia (Org.). Todas [as] distâncias: poemas, aforismos e ensaios de Beatriz Nascimento. Salvador: Ogum's Toques Negros, 2015. 
hooks, bell. Olhares negros: raça e representação. Tradução de Stephanie Borges. São Paulo: Elefante, 2019.

INSTITUTO DE PESQUISA ECONÔMICA E APLICADA; FÓRUM BRASILEIRO DE SEGURANÇA PÚBLICA (Org.) Atlas da violência 2020. Brasília: Ipea, FBSP, 2020. Disponível em: <https:// www.ipea.gov.br/atlasviolencia/download/24/atlas-da-violencia-2020.> Acesso em: 05 jan.2021

KILOMBA, Grada. Memórias da Plantação: Episódios de racismo cotidiano. Tradução: Jess Oliveira. - 1ed. - Rio de Janeiro: Cobogó, 2019.

NASCIMENTO, Beatriz. Insegurança. In: RATTS, Alex; GOMES, Bethânia (Org.). Todas [as] distâncias: poemas, aforismos e ensaios de Beatriz Nascimento. Salvador: Ogum's Toques Negros, 2015.

Ôrí (1989), Direção de: Raquel Gerber. Brasil, 1989.

PINACOTECA. Rosana Paulino: a costura da memória. Disponível em: <https://pinacoteca. org.br/programacao/rosana-paulino/> Acesso em: 10 jan.2021

RATTS, Alex; GOMES, Bethânia (Org.). Todas [as] distâncias: poemas, aforismos e ensaios de Beatriz Nascimento. Salvador: Ogum's Toques Negros, 2015. 